\title{
Economic evaluation of adherence to treatment guidelines in nonintensive care pneumonia
}

\author{
R. Menéndez*, S. Reyes*\#, R. Martínez*, P. de la Cuadra*, J. Manuel \\ Vallés* and J. Vallterra*
}

ABSTRACT: Guidelines have been developed to improve the treatment of community-acquired pneumonia (CAP) but information regarding their influence on costs is lacking. The aim of the present study was to conduct a cost-effectiveness analysis of CAP treatment from the hospital perspective when adhering to Spanish guidelines.

A prospective cohort study was performed in 271 patients with CAP admitted to a tertiary-care hospital, not needing intensive care. Collected data included patients' characteristics, comorbidity, initial risk class, resource use (medication, blood and microbiological analyses, and radiology) and economic data. Antimicrobial treatment was recorded as adherent or nonadherent to Spanish guidelines. Outcome measures were mortality and readmission at 30 days.

The median cost for adherent treatment was 1,665.5 versus 1,710.5 Euros for nonadherent treatment. Mortality and readmission were $10 \%$ and $2.1 \%$ for adherent treatment versus $13.6 \%$ and 6.2\% for nonadherent treatment. The cost-effectiveness ratio was 2,277 Euros per expected cure for patients treated according to the guidelines and 2,567 Euros per expected cure for the nonadherence group. The incremental cost-effectiveness ratio showed that adherence to treatment guidelines saved 1,121 Euros per patient cured compared with nonadherence. The sensitivity analysis demonstrated that the findings were robust.

An antimicrobial treatment according to guidelines is the dominant alternative due to its costeffectiveness.

KEYWORDS: Cost-effectiveness, mortality, pneumonia, readmission, treatment guidelines

ommunity-acquired pneumonia (CAP) is a frequent and serious disease with important socioeconomic impact. The incidence in adults is $160 \times 10^{5}$ cases $\cdot \mathrm{yr}^{-1}$ and is the main cause of death from infection in the USA and Europe [1, 2]. Healthcare resource consumption is high and involves direct and indirect health costs, the latter due mainly to lost work days.

The impact of the cost of the disease process on the healthcare budget is mainly caused by the cost of hospitalisation, which represents $70-90 \%$ of the total cost of CAP $[3,4]$. In Spain, the cost of respiratory infection is $\sim 115$ million Euros $\cdot \mathrm{yr}^{-1}$ [5].

Direct health costs caused by CAP were assessed by FINE et al. [6] and were identified as belonging to categories such as emergency treatment, laboratory analyses, diagnostic procedures, hospital stay and other incidental procedures. Hospital stay is responsible for the highest percentage and can reach $70 \%$ of the total cost.
The most recent guidelines for the management of CAP present recommendations regarding hospitalisation and discharge from hospital [7].

In order to decrease costs, there has been a tendency in recent years to reduce hospital stay using strategies that encourage early discharge [8-10]. However, METERSKY et al. [11] found that the progressive reduction in the duration of hospital stay was accompanied by an increase in CAP-associated mortality at 30 days and in rehospitalisation. These findings highlighted the difficulty in implementing measures directed towards restricting costs without considering its possible negative effect on disease prognosis. The evaluation of costs in clinical practice should have a perspective that includes both concepts, i.e. cost and effectiveness.

Scientific societies in Europe (e.g. European Respiratory Society) and the USA (e.g. American Thoracic Society) have published practice guidelines that include recommendations for empirical
AFFILIATIONS

*Pneumology Service, La Fe University Hospital, Valencia, and \#Programa Doctorado, Barcelona Autonomic University, Barcelona, Spain.

CORRESPONDENCE R. Menéndez

Servicio de Neumología Hospital Universitario La Fe Avda. De Campanar 21 46009 Valencia Spain Fax: 34961973089 E-mail: rmenend@separ.es

Received:

April 172006

Accepted after revision:

September 092006

STATEMENT OF INTEREST

None declared. 
antibiotic treatment. When the antibiotic treatment adheres to these guidelines better outcomes have been achieved with lower mortality rates. However, less is known regarding the impact on costs $[12,13]$. There is a dearth of information in existing CAP guidelines on the cost-effectiveness of the recommended antibiotic treatments [14] and future guidelines will need to contain this information or, at least, an evaluation of the different care options.

The objective of the present study was to conduct a pharmacoeconomic evaluation to determine if treatment adherence to the Spanish Society of Pneumology and Thoracic Surgery (SEQ-SEPAR) guidelines [15] is efficacious and whether it is cost-effective in the management of patients hospitalised with CAP, quantifying the costs from the perspective of the hospital.

\section{PATIENTS AND METHODS}

\section{Design and study population}

A prospective observational study of 13 months of duration was performed in a cohort of patients admitted to a public tertiary-care hospital. The inclusion criteria were: 1) age $>16$ yrs; 2) clinical picture compatible with CAP, with two or more of the following signs or symptoms: fever, new or increasing cough or sputum production, dyspnoea, pleuritic chest pain, new focal signs on chest examination; and 3) appearance of a new infiltrate in a simple chest radiography [16]. The exclusion criteria were: hospitalisation in the previous 10 days, admission to the intensive care unit (ICU), immunosuppression due to medication (except corticotherapy $<15 \mathrm{mg}$ day $^{-1}$ ), HIV positive infection, bronchoaspiration or tuberculosis. The study was approved by the local ethics committee. Informed consent was not considered necessary since there was no intervention on the process of treatment of CAP or on physicians' decisions.

Data collection included demographic and clinical data: age, sex, comorbidity (diabetes mellitus, chronic heart failure, chronic obstructive pulmonary disease, cerebrovascular disease, renal disease, liver disease or neoplasia), findings in the physical examination on admission (cardiac frequency, respiratory rates, temperature, blood pressure, mental status), laboratory tests (arterial blood gases, haematocrit, leukocyte count, glycaemia, blood urea, electrolytes and others), microbiological tests, radiographic studies and other relevant procedures. All the patients were classified according to initial severity according to the risk scale of Fine [17]. Initial empirical treatment was considered to comply with the Spanish guidelines [15] when it consisted of third-generation cephalosporin (cefotaxime or ceftriaxone) or amoxycillin-clavulanic acid in combination (optional) with a macrolide, or monotherapy with fluoroquinolone (third or fourth generation). All other antibiotic regimens were considered as nonadherent to the guidelines.

\section{Statistical analysis}

A descriptive analysis of the study group was carried out and parametric statistical analyses were used if the variable had a normal distribution and nonparametric analyses if not. The Chi-squared test was used for qualitative variables. The MannWhitney U-test was used for quantitative variables.

\section{Methodology for the pharmacoeconomic assessments}

Costs analysis

The analyses of costs were conducted from the perspective of the hospital. Direct health costs were identified and grouped into: 1) costs of pharmacotherapy (all doses of antibiotics and any other medication for treatment of comorbidity or complications); 2) diagnostic tests (including blood gas analysis, laboratory tests, blood cultures, other microbiological studies, ECG, chest radiographs and other incidental analyses); and 3) hospital room cost (cost per day multiplied by the number of days of stay).

All the costs were calculated in Euros for the year 2002. The medications costs were calculated using the mean cost of the drugs during the year 2002. The costs of the radiographic studies and of microbiological and other relevant tests, as well as the cost per day of hospital room, were obtained from the official fees of the Valencia Health Service (Official Bulletin DOGV No. 4409 [18]), the public healthcare provider of the present authors' region.

\section{Effectiveness: outcome measures}

The measure of overall effectiveness of treatment was the total number of patients cured. A patient was considered cured when they survived the episode of pneumonia and did not require readmission for 30 days.

\section{Cost-effectiveness and cost-minimisation analysis}

Cost was calculated separately for patients with treatment complying with the SEPAR guidelines (adherence group: A) and patients treated under other regimens (nonadherence group: NA). The total individual cost for groups A and NA can be calculated as the sum of the direct costs for each patient in groups A and NA. The overall cost for groups A and NA can be calculated as the sum of the costs for all patients in groups $A$ and NA. The quotient of cost $(\mathrm{C})$ divided by effectiveness (E), i.e. cost-effectiveness ratios $\mathrm{CA} / \mathrm{EA}$ and CNA/ENA, was calculated for both groups of patients by dividing the mean cost per patient by the probability of success for each group. The result is the mean cost per expected cure.

A cost-minimisation analysis was performed as follows: CACNA in order to calculate the difference in costs per patient between the two options. The incremental cost-effectiveness ratio (ICER) was also calculated (Equation 1). It is defined as the ratio of the difference in costs to the difference in effectiveness between two alternatives: adherence versus nonadherence:

$$
\mathrm{ICER}=(\mathrm{CA}-\mathrm{CNA}) /(\mathrm{EA}-\mathrm{ENA})
$$

The ICER is the measure primarily used to compare the costeffectiveness of a experimental treatment with a control treatment. A bootstrap nonparametric method for calculating confidence intervals (CI) for cost-effectiveness ratios was used [19].

\section{Sensitivity analysis}

Sensitivity analysis was performed to evaluate the robustness of the results. The procedure involves modifying the data input variables using a wide range of values, usually applied to cost variables, and is a measure of the internal and external validity of the assessment. The results are considered robust if the modifications of the variables do not produce significant 
changes in the outcome. The present authors elected to modify the variables that carried the greatest weight in the cost estimations. The calculation of cost-effectiveness was then repeated, substituting each one of the original values with the value derived from the extremes of the $95 \% \mathrm{CI}$.

\section{RESULTS}

The study included 271 patients. Table 1 summarises the demographic characteristics, initial severity of disease and clinical progress in the 190 patients of group A and the 81 patients of group NA. Nonadherent treatments were: secondgeneration cefalosporin \pm macrolide in 30 patients, macrolides in monotherapy in 19 , ciprofloxacin \pm another antibiotic in 19 , ceftazidime \pm another antibiotic in 10 and other regimens in three. There were no significant differences in demographic variables, comorbidity or initial severity. Overall mortality was $11 \%$ (30 out of 271 ), with $10 \%$ (19 out of 190 ) in group A versus $13.6 \%$ (11 out of 81 ) in group NA $(\mathrm{p}=0.3)$ The overall mean $\pm S D$ duration of hospitalisation was $9.8 \pm 5.5$ days: $9.7 \pm 5.2$ in group $\mathrm{A}$ and $10.1 \pm 6.2$ in group NA $(p=0.7)$. Four patients $(2 \%)$ in group A and $11(6 \%)$ in group NA were readmitted within 30 days $(p=0.1$ and $p>0.05$, respectively).

\begin{tabular}{|c|c|c|c|c|}
\hline \multirow[t]{3}{*}{ TABLE 1} & \multicolumn{4}{|c|}{$\begin{array}{l}\text { Demographic characteristics, comorbidity and } \\
\text { initial risk class in the groups with and without } \\
\text { treatment guidelines adherence (univariate } \\
\text { analysis) }\end{array}$} \\
\hline & & \multicolumn{2}{|c|}{ Adherence to guidelines } & \multirow[t]{2}{*}{ p-value } \\
\hline & & Yes & No & \\
\hline \multicolumn{2}{|c|}{ Subjects $n$} & 190 & 81 & \\
\hline \multicolumn{2}{|c|}{ Sex male/female } & $82 / 108$ & $28 / 53$ & 0.1 \\
\hline \multicolumn{2}{|c|}{ Age yrs } & $69.4 \pm 15.6$ & $72.3 \pm 14$ & 0.1 \\
\hline \multicolumn{2}{|l|}{ Nursing home } & 5 (2.6) & $3(3.7)$ & 0.6 \\
\hline \multicolumn{2}{|l|}{ Smoking habit } & $31(16.3)$ & $10(12.1)$ & 0.3 \\
\hline \multicolumn{2}{|c|}{$\begin{array}{l}\text { Hospitalisation during } \\
\text { previous year }\end{array}$} & $58(30.5)$ & $24(29.6)$ & 0.8 \\
\hline \multicolumn{2}{|c|}{ Prior antibiotic } & $71 / 190(37.3)$ & 25/81 (30.8) & 0.3 \\
\hline \multicolumn{2}{|l|}{ Diabetes } & $40(21.1)$ & $17(21)$ & 0.9 \\
\hline \multicolumn{2}{|l|}{ Neoplasia } & $10(5.3)$ & $3(3.7)$ & 0.5 \\
\hline \multicolumn{2}{|l|}{ Liver disease } & $6(3.2)$ & $3(3.7)$ & 0.5 \\
\hline \multicolumn{2}{|l|}{ Heart failure } & $65(34.2)$ & $24(29.6)$ & 0.4 \\
\hline \multicolumn{2}{|c|}{$\begin{array}{l}\text { Cerebrovascular } \\
\text { disease }\end{array}$} & $21(11.1)$ & $10(12.3)$ & 0.7 \\
\hline \multicolumn{2}{|c|}{ Renal disease } & $12(6.3)$ & $4(4.9)$ & 0.6 \\
\hline \multicolumn{2}{|l|}{ COPD } & $42(22.1)$ & 27 (33.3) & 0.06 \\
\hline \multicolumn{5}{|l|}{ Fine risk class } \\
\hline \multicolumn{2}{|l|}{1} & $19(10)$ & $3(3.7)$ & 0.09 \\
\hline \multicolumn{2}{|l|}{$\|$} & $23(12.1)$ & $13(16)$ & \\
\hline \multicolumn{2}{|l|}{ III } & $31(16.3)$ & $22(27.2)$ & \\
\hline \multicolumn{2}{|l|}{ IV } & $84(44.2)$ & $29(35.8)$ & \\
\hline \multicolumn{2}{|l|}{$\mathrm{V}$} & $33(17.4)$ & $14(17.3)$ & \\
\hline
\end{tabular}

Data are presented as mean \pm SD or $n(\%)$, unless otherwise stated. COPD: chronic obstructive pulmonary disease.

\section{Economic calculations: cost-minimisation and cost- effectiveness analysis}

The mean cost of in-patient treatment for the whole cohort was $2,025 \pm 1.197$ Euros. The mean cost for each component was: drug treatment $267 \pm 317$ Euros, laboratory and diagnostic tests $353.9 \pm 297$ Euros and hospital room 1,403 \pm 789 Euros. The separate results for groups are shown in table 2. Adherence resulted in better patient outcome ( $88 \%$ versus $81 \%$ cured patients) and at lower cost, although without reaching statistical significance $(\mathrm{p}>0.05)$. Two economic evaluation methods were performed: 1) a cost-minimisation analysis, since the difference in outcome between the two options was not found statistically significant; and 2) a cost-effectiveness analysis with a bootstrapping method, since the present study was not designed to show equivalence of treatments.

\section{Cost-minimisation analysis}

The incremental cost between the two options was 78.5 Euros (95\% CI -261.7-418.7). Adherence to SEPAR guidelines saved 78.5 Euros per patient when compared with nonadherence.

\section{Cost-effectiveness analysis}

The cost-effectiveness ratio $(\mathrm{C} / \mathrm{E})$ or mean cost per patient cured was 2,277 Euros in group A and 2,567 Euros in group NA. The ICER was negative, which indicates that the treatment according to the guidelines had a saving of 1,121 Euros per cured patient compared with the alternative option of nonadherence. A bootstrapping nonparametric method was employed using 2,000 re-samples in order to perform a stochastic analysis. The ICER for this bootstrap re-sample was -942.7 Euros (95\% CI -1,885.8-0.37). The ICER had values $<1,256$ Euros in $80 \%$ and $<3,616$ Euros in $90 \%$ of re-samples.

\section{Sensitivity analysis}

Three sensitivity analyses were performed with the different compartments of the total costs, including: antibiotics, hospital stay, laboratory tests and diagnostic evaluations. For each sensitivity analysis, all the costs were re-calculated using the extreme limits of the $95 \%$ CI of each compartment. For upper and lower limit of the $95 \%$ CI of the mean (table 3), the mean cost per patient in the two groups was re-calculated as well as the cost-effectiveness ratio and the incremental cost-effectiveness ratio.

The results (table 4) showed that the cost-effectiveness results remained stable despite being subjected to wide variations in the distinct cost components.

\section{DISCUSSION}

The most relevant results of the present study are: 1) adherence to guidelines is quite high; 2) adherence to guidelines in the empirical treatment of CAP is a dominant option since the outcomes are more effective compared with nonadherence ( $88 \%$ versus $81 \%$ cured patients) and less expensive $(2,001$ versus 2,079 Euros), as demonstrated by the cost-effectiveness analysis; 3) a cost-minimisation analysis showed that adherence to guidelines saved 78.5 Euros per patient; and 4) the incremental cost-effectiveness ratio showed that adherence to guidelines saved 1,121 Euros per patient cured compared with the nonadherence option. 
TABLE 2 Cost results in the adherent and nonadherent group

\begin{tabular}{lccc} 
& \multicolumn{3}{c}{ Adherence to guidelines } \\
\cline { 2 - 4 } & Yes & No \\
\hline Overall treatment cost & $257.9 ; 190.9(113.6-303.3)$ & $289.3 ; 181.1(114.5-311.3)$ \\
$\quad$ Antibiotics & $176.8 ; 139.3(82.8-227.4)$ & $170.8 ; 135.2(73.6-236.8)$ & 0.8 \\
$\quad$ Other & $80.3 ; 38.0(14.9-68.3)$ & $118.5 ; 37.7(22.4-69.6)$ & 0.6 \\
Diagnostic/laboratory test & $355.8 ; 291.5(216.7-393.7)$ & $349.2 ; 283.0(213.5-391.0)$ & 0.3 \\
Hospital stay & $1387.3 ; 1142.9(857.2-1750.1)$ & $1441.0 ; 1285.8(857.2-1714.4)$ & 0.6 \\
Total costs & $2001.1 ; 1665.5(1294.8-2513.1)$ & $2079.6 ; 1710.5(1181.2-2366.7)$ & 0.8 \\
\hline
\end{tabular}

Data are presented as mean; median (25th-75th percentiles). Costs are provided in Euros.

Guidelines of scientific societies assist the attending physician in the selection of treatment and their objective is to improve the outcome. In the present study, adherence to Spanish guidelines was rather high $(70 \%)$ and was similar to that described in the literature, although there is a wide variation among hospitals and physicians [20-22]. Several factors might explain noncompliance with guidelines: various specialists prescribing treatment in emergency rooms, the inertia of previous practice $(>50 \%$ second-generation cefalosporin \pm macrolide or macrolide alone) or different perception of the influence of the guidelines' benefit [23], although in the present study this interesting topic was not specifically investigated. No significant differences were found for the treatment of patients based on age, sex, comorbidity and initial severity.

The efficacy of adherence to initial empirical treatment guidelines has been evaluated for its impact on mortality, clinical response, duration of hospital stay and, less systematically, on cost $[12,14,20]$. There are several studies that found a lower mortality when treatment was compliant with guidelines [13, $14,21,24]$ and, furthermore, a more rapid clinical stability was achieved [25]. However, there remains a lack of studies performing a pharmacoeconomic evaluation focusing on costs $[15,26]$. A cost-effectiveness analysis (CEA) is a useful tool when evaluating costs and outcomes with different treatment

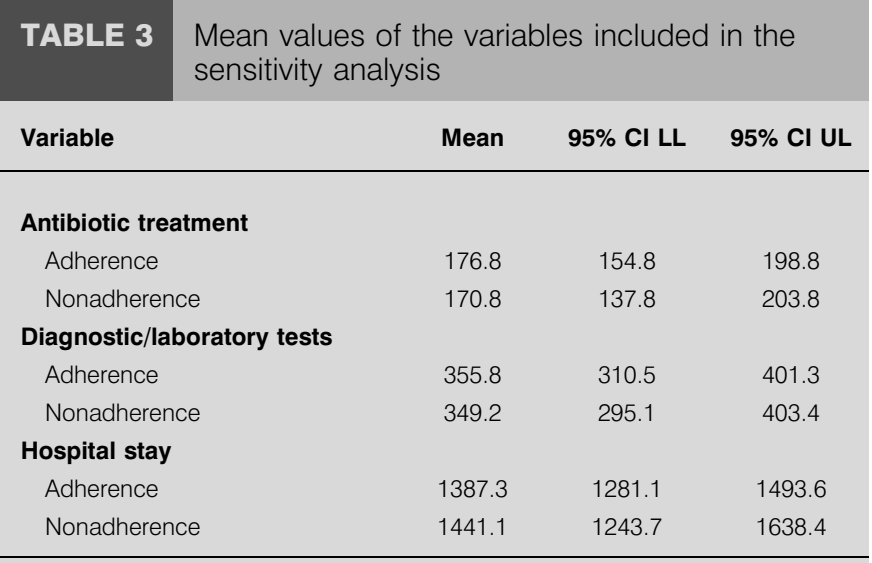

Cl: confidence interval; LL: lower limit; UL: upper limit. Costs are provided in Euros. modalities. As such, it is ideal in the present context [27, 28] even when no statistically significant differences have been demonstrated in the current study. In fact, a CEA is considered an appropriate analysis when a lack of significance is found

\begin{tabular}{|c|c|c|c|c|c|c|}
\hline \multirow[t]{2}{*}{ TABLE 4} & \multicolumn{6}{|c|}{$\begin{array}{l}\text { Results of cost-effectiveness and sensitivity } \\
\text { analysis comparing adherence and } \\
\text { nonadherence treatment groups }\end{array}$} \\
\hline & & C & $E \%$ & $C / E$ & ICER & Result \\
\hline \multicolumn{7}{|c|}{ Cohort analysis } \\
\hline Adherenc & & 2001 & 88 & 2276.7 & -1121 & Dominant \\
\hline Nonadher & & 2079 & 81 & 2566.6 & & \\
\hline \multicolumn{7}{|c|}{ Sensitivity analysis 1} \\
\hline \multicolumn{7}{|c|}{ Treatment } \\
\hline \multicolumn{7}{|c|}{ 95\% CI LL } \\
\hline Adhe & & 2251.7 & 88 & 2558.7 & -3715 & Dominant \\
\hline Nona & erence & 2511.8 & 81 & 3100.9 & & \\
\hline \multicolumn{7}{|c|}{$95 \% \mathrm{Cl}$ UL } \\
\hline Adhe & & 2301.8 & 88 & 2615.7 & -4155.7 & Dominant \\
\hline Nona & erence & 2592.7 & 81 & 3200.8 & & \\
\hline \multicolumn{7}{|c|}{ Sensitivity analysis 2} \\
\hline \multicolumn{7}{|c|}{ Diagnostics } \\
\hline \multicolumn{7}{|c|}{ 95\% Cl LL } \\
\hline Adhe & & 2225.1 & 88 & 2528.5 & -3724 & Dominant \\
\hline Nona & erence & 2485.8 & 81 & 3068.8 & & \\
\hline \multicolumn{7}{|c|}{$95 \%$ CI UL } \\
\hline Adhe & & 2328.4 & 88 & 2645.9 & -4147 & Dominant \\
\hline Nona & erence & 2618.7 & 81 & 3232.9 & & \\
\hline \multicolumn{7}{|c|}{ Sensitivity analysis 3} \\
\hline \multicolumn{7}{|c|}{ Hospitalisation } \\
\hline \multicolumn{7}{|c|}{$95 \% \mathrm{Cl}$ LL } \\
\hline Adhe & & 2155.8 & 88 & 2449.7 & -2.202 & Dominant \\
\hline Nona & erence & 2310.1 & 81 & 2851.9 & & \\
\hline \multicolumn{7}{|c|}{$95 \% \mathrm{CI} U \mathrm{~L}$} \\
\hline Adhe & & 2397.6 & 88 & 2724.5 & -5670 & Dominant \\
\hline Nona & erence & 2794.5 & 81 & 3450.8 & & \\
\hline
\end{tabular}

Costs are provided in Euros. C: cost; E: effectiveness; C/E: cost-effectiveness ratio; ICER: incremental cost-effectiveness ratio (mean cost per additional patient cured); Dominant: lower cost and better outcomes; Cl: confidence interval; LL: lower limit; UL: upper limit. 
and the study was not designed to demonstrate equivalence [26]. Some previous studies about costs have been focused on strategies to decrease admissions to hospital due to CAP [29]. However, it has been reported that while a reduction in admissions was possible, there was an increase in subsequent readmissions and a lower satisfaction of the patients [30]. In that and other studies, the main goal had been to contain costs without compromising patient outcomes [31,32]. These studies provide valuable information for clinical practice despite the fact that their objectives had focused on avoiding adverse effects, rather than on efficacy.

Although guidelines stress the importance of implementing and maintaining adherence to the recommendations, there has been a paucity of data published about their impact on the cost-effectiveness of the treatment. In nonhospitalised patients with CAP, GLEASON et al. [33] found that adherence to the American Thoracic Society guidelines was associated with a reduction of costs in patients $<60$ yrs of age and, conversely, with an increase in those of $>60$ yrs of age with comorbidities.

In the present study, it was decided to include all the components of hospital costs since the selection of antibiotics influences other prognostic variables, such as treatment failure and clinical stability, which are related to length of hospital stay. As a measure of effectiveness the recovery of pneumonia (defined as the patient surviving the episode of pneumonia and not needing readmission within 30 days of discharge) was used. These outcome indicators are universally applicable and are widely accepted [32, 34, 35].

ORRICK et al. [36] compared the cost of care for patients hospitalised with CAP. They found that the median cost of hospitalisation was higher when treatment was not compliant with guideline recommendations (US\$3,085 versus US\$2,047). However, the authors did not perform any cost-effectiveness analyses. Recently, BAUER et al. [37] reported that patients treated with moxifloxacin benefited from an earlier discharge, although direct costs and clinical efficacy were similar to other antibiotics.

In the present study it was found that adherence to the guidelines was the cost-effective option since the ratio was 2,277 Euros per expected cure versus 2,567 Euros in those with nonadherent treatments. This produced a negative incremental cost-effectiveness ratio since adherence saved 1,121 Euros per patient cured compared with nonadherence. A bootstrapping analysis demonstrated that in $95 \%$ of cases adherence to guidelines saves costs [19]. Furthermore, the additional cost of readmission was reduced when the treatment was adherent. The sensitivity analysis demonstrated that the results found in the cost-effectiveness analysis remain stable despite using wide variations in the different components introduced into the cost equations.

As a limitation of the present study it should be highlighted that there was no evaluation of the impact on indirect cost, such as patient-reported lost days of normal activity. Also, the present study was observational and nonrandomised. Furthermore, patients with admission to ICU were not included in the present study since it is one of the highest determinants of cost in CAP [37].
In summary, for patients hospitalised with communityacquired pneumonia, treatment according to the guidelines is the dominant alternative due to its cost-effectiveness.

\section{REFERENCES}

1 Armstrong GL, Conn LA, Pinner RW. Trends in infectious disease mortality in the United States during the 20th century. JAMA 1999; 281: 61-66.

2 Kaplan V, Angus DC, Griffin MF, Clermont G, Scott Watson R, Linde-Zwirble WT. Hospitalized communityacquired pneumonia in the elderly: age- and sex-related patterns of care and outcome in the United States. Am J Respir Crit Care Med 2002; 165: 766-772.

3 Lave JR, Fine MJ, Sankey SS, Hanusa BH, Weissfeld LA, Kapoor WN. Hospitalized pneumonia. Outcomes, treatment patterns, and costs in urban and rural areas. J Gen Intern Med 1996; 11: 415-421.

4 Guest JF, Morris A. Community-acquired pneumonia: the annual cost to the National Health Service in the UK. Eur Respir J 1997; 10: 1530-1534.

5 Monge V, San-Martin VM, Gonzalez A. The burden of community-acquired pneumonia in Spain. Eur J Public Health 2001; 11: 362-364.

6 Fine MJ, Pratt HM, Obrosky DS, et al. Relation between length of hospital stay and costs of care for patients with community-acquired pneumonia. Am J Med 2000; 109: 378-385.

7 Niederman MS, Mandell LA, Anzueto A, et al. Guidelines for the management of adults with community-acquired pneumonia. Diagnosis, assessment of severity, antimicrobial therapy, and prevention. Am J Respir Crit Care Med 2001; 163: 1730-1754.

8 Rhew DC, Tu GS, Ofman J, Henning JM, Richards MS, Weingarten SR. Early switch and early discharge strategies in patients with community-acquired pneumonia: a metaanalysis. Arch Intern Med 2001; 161: 722-727.

9 Siegel RE. Strategies for early discharge of the hospitalized patient with community-acquired pneumonia. Clin Chest Med 1999; 20: 599-605.

10 Weingarten S, Riedinger MS, Sandhu M, et al. Can practice guidelines safely reduce hospital length of stay? Results from a multicenter interventional study. Am J Med 1998; 105: 33-40.

11 Metersky ML, Tate JP, Fine MJ, Petrillo MK, Meehan TP. Temporal trends in outcomes of older patients with pneumonia. Arch Intern Med 2000; 160: 3385-3391.

12 Menéndez R, Ferrando D, Valles JM, Vallterra J. Influence of deviation from guidelines on the outcome of community-acquired pneumonia. Chest 2002; 122: 612-617.

13 Dean NC, Silver MP, Bateman KA, James B, Hadlock CJ, Hale D. Decreased mortality after implementation of a treatment guideline for community-acquired pneumonia. Am J Med 2001; 110: 451-457.

14 Nathwani D, Rubinstein E, Barlow G, Davey P. Do guidelines for community-acquired pneumonia improve the cost-effectiveness of hospital care? Clin Infect Dis 2001; 32: 728-741.

15 Frias J, Gomis M, Prieto J, et al. [Initial empirical antibiotic treatment of community-acquired pneumonia]. Rev Esp Quimioter 1998; 11: 255-261. 
16 Dorca J, Bello S, Blanquer J, et al. [The diagnosis and treatment of community-acquired pneumonia. SEPAR. Sociedad Española de Neumología y Cirugía Torácica]. Arch Bronconeumol 1997; 33: 240-246.

17 Fine MJ, Auble TE, Yealy DM, et al. A prediction rule to identify low-risk patients with community-acquired pneumonia. N Engl J Med 1997; 336: 243-250.

18 Diari Oficial de la Generalitat Valenciana. www.docv. gva.es/portal/portal/2002/12/31/pdf/doc/2002_14538.pdf. Date last updated: December 31 2002. Date last accessed: May 312003.

19 Campbell MK, Torgerson DJ. Bootstrapping: estimating confidence intervals for cost-effectiveness ratios. QJM 1999; 92: 177-182.

20 Mortensen EM, Restrepo M, Anzueto A, Pugh J. Effects of guideline-concordant antimicrobial therapy on mortality among patients with community-acquired pneumonia. Am J Med 2004; 117: 726-731.

21 Menéndez R, Torres A, Zalacain R, et al. Guidelines for the treatment of community-acquired pneumonia: predictors of adherence and outcome. Am J Respir Crit Care Med 2005; 172: 757-762.

22 Marras TK, Chan CK. Use of guidelines in treating community-acquired pneumonia. Chest 1998; 113: 1689-1694.

23 Cabana MD, Rand CS, Powe NR, et al. Why don't physicians follow clinical practice guidelines? A framework for improvement. JAMA 1999; 282: 1458-1465.

24 Gleason PP, Meehan TP, Fine JM, Galusha DH, Fine MJ. Associations between initial antimicrobial therapy and medical outcomes for hospitalized elderly patients with pneumonia. Arch Intern Med 1999; 159: 2562-2572.

25 Menéndez R, Torres A, Rodríguez de Castro F, et al. Reaching stability in community-acquired pneumonia: the effects of the severity of disease, treatment, and the characteristics of patients. Clin Infect Dis 2004; 39: 1783-1790.

26 Briggs AH, O'Brien BJ. The death of cost-minimization analysis? Health Econ 2001; 10: 179-184.

27 Detsky AS, Naglie IG. A clinician's guide to cost-effectiveness analysis. Ann Intern Med 1990; 113: 147-154.

28 Russell LB, Gold MR, Siegel JE, Daniels N, Weinstein MC. The role of cost-effectiveness analysis in health and medicine. Panel on Cost-Effectiveness in Health and Medicine. JAMA 1996; 276: 1172-1177.

29 Marrie TJ, Lau CY, Wheeler SL, Wong CJ, Vandervoort MK, Feagan BG. A controlled trial of a critical pathway for treatment of community-acquired pneumonia. CAPITAL Study Investigators. Community-Acquired Pneumonia Intervention Trial Assessing Levofloxacin. JAMA 2000; 283: 749-755.

30 Atlas SJ, Benzer TI, Borowsky LH, et al. Safely increasing the proportion of patients with community-acquired pneumonia treated as outpatients: an interventional trial. Arch Intern Med 1998; 158: 1350-1356.

31 Ramírez JA, Vargas S, Ritter GW, et al. Early switch from intravenous to oral antibiotics and early hospital discharge: a prospective observational study of 200 consecutive patients with community-acquired pneumonia. Arch Intern Med 1999; 159: 2449-2454.

32 Weingarten SR, Riedinger MS, Hobson P, et al. Evaluation of a pneumonia practice guideline in an interventional trial. Am J Respir Crit Care Med 1996; 153: 1110-1115.

33 Gleason PP, Kapoor WN, Stone RA, et al. Medical outcomes and antimicrobial costs with the use of the American Thoracic Society guidelines for outpatients with community-acquired pneumonia. JAMA 1997; 278: 32-39.

34 Gilbert K, Gleason PP, Singer DE, et al. Variations in antimicrobial use and cost in more than 2,000 patients with community-acquired pneumonia. Am J Med 1998; 104: 1727.

35 Meehan TP, Weingarten SR, Holmboe ES, et al. A statewide initiative to improve the care of hospitalized pneumonia patients: The Connecticut Pneumonia Pathway Project. Am J Med 2001; 111: 203-210.

36 Orrick JJ, Segal R, Johns TE, Russell W, Wang F, Yin DD. Resource use and cost of care for patients hospitalised with community acquired pneumonia: impact of adherence to infectious diseases society of america guidelines. Pharmacoeconomics 2004; 22: 751-757.

37 Bauer TT, Welte T, Ernen C, et al. Cost analyses of community-acquired pneumonia from the hospital perspective. Chest 2005; 128: 2238-2246. 